\title{
Energy Consumption and Optimization in Process Industries
}

\author{
Faraz Ahmad ${ }^{1}$, Dr. R. K. Jain ${ }^{2}$ \\ ${ }^{1,2}$ Department of Mechanical Engineering, ITM University, NH-75 Jhansi road, Gwalior, MP, India
}

\begin{abstract}
Developing countries and the economies in transition account for 60\% of industry's total final energy consumption. Industry has significantly improved its energy efficiency in recent decades. But industry's total energy use continues to grow as a result of continuing large increases in the volume of production. Production is expected to continue to expand very substantially in the coming decades, particularly in developing countries. As a result, modest energy efficiency improvement rates will not be sufficient to stabilize or decrease the sector's energy demand in absolute terms. In order to make significant reductions, ambitious energy savings measures need to be implemented. The paper aims to have optimized and reliable production processes, provided energy efficiency measures are implemented in the correct way. There is hence, critical concern regarding the understanding of application issues involved in retrofitting. This essentially means the changes which might take place in the performance of the system or the machine, while carrying out retrofitting for improved energy efficiency.
\end{abstract}

Keywords: Energy consumption, energy efficiency, process industries, energy conservation, Optimized production

\section{Introduction}

The process industries are those industries where the primary production processes are either continuous, or occur on a batch of materials that is indistinguishable. Examples of the process industries include food, beverages, chemicals, pharmaceuticals, petroleum, ceramics, base metals, coal, plastics, rubber, textiles, tobacco, wood and wood products, paper and paper products, etc.

Process manufacturing is the production of goods that are typically produced in bulk quantities, as opposed to discrete and countable units. Industrial processes are procedures involving chemical, physical, electrical or mechanical steps to aid in the manufacturing of an item or items, usually carried out on a very large scale. Industrial processes are the key components of heavy industry. The production of process goods usually requires inputs for thermal or chemical conversion, such as heat, time and pressure. The product typically cannot be disassembled to its constituent parts.

\section{Literature Survey}

With the opening up of the Indian economy during the early nineties, the industrial sector has Awaken to the need of reducing the cost of production [1] thereby trying to make their products more competitive in the market. Energy has become one of the crucial areas where cost reduction is targeted. Efforts in this direction have lead to positive results.

The specific energy consumption of some of the energy intensive sectors reflects this change. While there are reasons for the industries to feel proud of this positive change, a comparative analysis shows that the same industries are way behind their international competitors.

There are essentially two approaches to improving energy efficiency in Indian industries - the first involves adoption of new and energy efficient process [2] and the second involves improving operating efficiency of the existing systems and methods. Acquiring new technology requires financial, technical, and institutional resources. There are several instances of such changes already taking place in some of the energy intensive sectors. However, there is still an enormous efficiency gain possible by improving operations.

Experience shows that at least $10 \%$ to $15 \%$ reduction in the energy cost is possible through improved operations. Improved operation [3] primarily refers to retrofitting parts of the operating process, improving maintenance practicesstill less resource intensive as measures, than acquiring new technology. Though competition in the liberalized markets are forcing industries to cut energy costs, certain attitudes and mindsets act against this change towards more efficient production system for improved operations. Production is assigned greater importance with scant regard for operating efficiency. This attitude is not only prevalent, but appears dominant in industry. As a result, there is in general reluctance for any modification in a production system even when it improves the energy efficiency of a process. There is a fear that any disruption in the production process could cost the industry and amount to financial losses. This is often reflected in the form of oversized and inefficient production systems.

It is possible to have optimized [4] and reliable production processes, provided energy efficiency measures are implemented in the correct way. There is hence, critical concern regarding the understanding of application issues involved in retrofitting. This essentially means the changes which might take place in the performance of the system or the machine, while carrying out retrofitting for improved energy efficiency. For example, when replacing an oversized motor by the right sized motor for improving the energy efficiency - will the replaced motor be able to start and operate the machine? Even if there are slight risks of motor burnout, then implementing such a change would actually cost a huge amount to the industry by way of production loss. One can cite many examples to highlight this concern. It is 


\section{International Journal of Science and Research (IJSR) \\ ISSN (Online): 2319-7064}

Index Copernicus Value (2013): 6.14 | Impact Factor (2014): 5.611

through the understanding of the application issues that these industrial reliability concerns can be addressed. Therefore, case studies of successful retrofitting highlighting the critical issues could be a useful exercise in this direction. This could be done through insistence of post implementation audits. Computer simulation of systems and processes could also help in resolving the application issues involved in process modification. The role of other players in this area namely the equipment suppliers and the energy consultants, assume great importance in creating examples of successful energy efficiency projects. Equipment suppliers have been playing a major role in demonstrating energy savings through retrofitting inefficient system in industries. They have in turn gained from such aggressive campaigns and also contributed to creating awareness of energy efficiency in Indian industries [5]. This however, has taken place in a few instances only. Manufacturers believe that the market is not yet ready for energy efficiency and hence limited opportunities for business. One of the reasons cited for this belief is the buyer's concern to minimize the initial investment.

It is clear that even though industries realize the importance of energy conservation [6] as an area to minimize production cost there are number of obstacles which hinder the rational use of energy. These are inhibiting attitudes, insufficient technical know-how, market distortions, capital shortage etc. There is hence a need to design interventions in terms of policies and institutions which address these issues and create incentives for energy conservation in such industries.

\section{Energy consumption and its availability}

The entire energy consumption study of foundry is divided into three parts:

(1) Present Indian Energy Scenario

(2) Energy consumption in Process Industries

(3) Need for Energy conservation.

In the present energy scenario [7], India is importing about $30 \%$ of its total commercial energy supplies in the form of oil, coal, and even electricity to meet its ever-increasing demands. It is very serious matter from point of view of energy availability and demand. To eliminate the gap between availability and demand, efforts are being made to increase capacity of energy generation. Energy requirements can also be reduced without foregoing any end use benefits through efficient use of energy and elimination of wasteful energy. It will lead to energy savings. The approach has to be "Effectiveness of Energy Use" and "Energy savings" rather than of "Energy Input".

The natural sources of energy are depleting fast. As per the survey conducted and reports published by several national \& international agencies the energy consumption in Indian Process Industries is much above the required limits and has to be drastically reduced [8], [9].

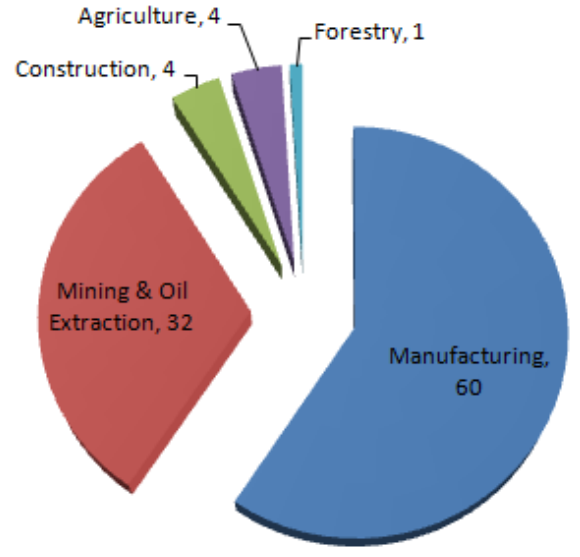

Figure 1: Energy Consumption in Industries

The energy conservation [10], [11] in Process Industries is important due to the following facts:-

1)Existing source of energy (Coal, oil, etc) are depleting fast.

2) Cost of product increases because of extra energy consumption.

3)High energy consumption increases the emission levels.

\subsection{Factors which influence energy consumption}

Such differences may largely be attributed to a multitude of factors, several of which are listed below:

1. Plant capacity

2. Rate of plant utilization

3. Equipment and the manufacturing process adopted

4. Integrated or non-integrated operation

5. Site layout

6. Overall efficiency of operation

7. Degree of mechanization of materials handling

8. Extent of process automation

9. Product type and mix

10. Degree of product finishing

11. Climatic conditions

12. Energy prices

13. Load factor

14. Steam and power balances

15. Extent of energy conservation measures adopted

16. Standard of maintenance

\section{Problems being faced by Indian Process Industry}

The following problems [12] are being faced by Indian Process Industry [6] are -

(1) Raw material supply

(2) Energy consumption and its availability

(3) Restriction by Central Pollution Control Board

(4) Technology up gradation

(5) Power requirements

(6)Impact of Globalization

\subsection{Requirement of Energy efficient Technique for Process Industry}

The process industries have a special responsibility in caring for the environment, because production and use of energy 


\section{International Journal of Science and Research (IJSR) \\ ISSN (Online): 2319-7064 \\ Index Copernicus Value (2013): 6.14 | Impact Factor (2014): 5.611}

from fossil fuels have major environmental impact [13], primarily through the emission of carbon monoxide, carbon di-oxide and sulphur di-oxide and suspended particulate matters. The solution lies in:

1) Minimizing the fuel consumption.

2) Developing cleaner technologies.

3) Searching for cleaner fuels.

For meeting the CPCB norms, one way is to use different pollution control equipments like high-energy scrubbers, bag filters, and electrostatic precipitators. However, they are expensive and also consuming more energy. The better alternative, as suggested by the Hon'ble Supreme Court is to clear up the emission of foundries by using suitable technologies to bring down the emission level.

Therefore technology used for the process industry must use minimum fuel and emission level of exhaust gases generated must be within the CPCB norms. This needs the design and development of an eco-friendly and energy efficient techniques for process industry [14]. It will also help in following the orders of Humble Supreme Court, and ultimately prevent the collapse of foundry industry in our country.

\subsection{Pattern of Energy Input}

Although there has been a marked change in recent years in the industry's attitude towards the introduction of energy saving equipment and the adoption of conservation measures, the national trends for the industry over the past decade, in the selected countries examined, indicate an upward swing in consumption of between 20-40 percent per unit of product in most cases [15].

Such a rise may be generally attributed to the introduction of highly mechanized equipment and automated systems, with the object of increasing production and reducing manning levels. Also, more mills are kiln-drying their sawn wood and the drying of chips is now becoming widespread in the particleboard industry, combined with an overall increase in product finishing.

\section{Energy Saving Techniques}

An analysis of survey undertaken in different process industries of India reveals that energy consumption of process industry is very high due to the following factors:

1)Diversity in shape and design of equipments for Process industry

2)Inappropriate use of refractory material

3)Inadequate insulation.

4)Deficiencies in combustion equipment.

5)Lack of temperature control equipments.

6)Poor maintenance.

Due to the above factors the efficiency of the process industry varied from 30 to $35 \%$ against the desired value of 50 to $55 \%$. The important parameters to be considered for an increase in efficiency are -
1) Maximum energy utilization

2) Minimizing the down time

3) Reducing heat losses.

4) Controlling heat losses

The need is of maximum "energy saving" in the process industry [16]. This can also partially be achieved by adopting "Energy Conservation" techniques. By controlling heat losses suitably the 6-8\% energy can be saved.

\subsection{Technology up-gradation}

The Indian process Industry is the blend of both modern and old technology. A large percentage of small scale process industry has now become obsolete due to use of old technology. The use of obsolete and primitive technology in such foundries result in:-

(1) Low productivity

(2) Inferior quality of product

(3) Unfavorable working conditions.

(4) More rejection

(5) More Energy consumption

(6) More pollution

(7) More Wastage of material

Several foreign countries like USA, U.K., Germany, Japan and Belgium are collaborating with Indian process industry for providing technical knowhow [17] and financial assistance. Most of Indian industries are manufacturing components for their foreign counter parts. Government Of India has encouraged technology transfer through joint venture with foreign companies.

\section{Conclusions}

It is clear that even though industries realize the importance of energy conservation as an/area to minimize production cost there are number of obstacles which hinder the rational use of energy. These are inhibiting attitudes, insufficient technical know-how, market distortions, capital shortage etc. There is hence a need to design interventions in terms of policies and institutions which address these issues and create incentives for energy conservation in such industries [18].

Equipment suppliers have been playing a major role in demonstrating energy savings through retrofitting inefficient system in industries. They have in turn gained from such aggressive campaigns and also contributed to creating awareness of energy efficiency in Indian industries. This however, has taken place in a few instances only. Manufacturers believe that the market is not yet ready for energy efficiency and hence limited opportunities for business. One of the reasons cited for this belief is the buyer's concern to minimize the initial investment.

\section{References}

[1] Mahapatra, S. and Mohanty, S. (2007). Lean Manufacturing in continuous process industry: An Emperical Study. Journal of Scientific and Industrial Research, 66, pp.19-27. 


\section{International Journal of Science and Research (IJSR) \\ ISSN (Online): 2319-7064}

Index Copernicus Value (2013): 6.14 | Impact Factor (2014): 5.611

[2] Rossiter, A. and Jones, B. (2015). Energy management and efficiency for the process industries. New Jersey: Wiley.

[3] Bhattacharjee, K. and Tyagi, A. (2001). Industrial energy conservation: issues for improving industrial operations. TERI Newswire, 7(17).

[4] Energy Management and Energy Optimization in the Process Industry. (2011). White paper.

[5] Energy Management For Process Industries. (2011). Control Engineering Asia, pp.16-17.

[6] Energy Management Solution For Process Industries. (2009). cpmPlus Energy Manager, pp.1-12.

[7] Fact Sheet: Energy use in the steel industry. (2014). World Steel Association.

[8] Porzio, G., Fornai, B., Amato, A., Matarese, N., Vannucci, M., Chiappelli, L. and Colla, V. (2013). Reducing the energy consumption and $\mathrm{CO} 2$ emissions of energy intensive industries through decision support systems - An example of application to the steel industry. Applied Energy, 112, pp.818-833.

[9] Energy Consumption in the UK. (2015). Department of energy and Climate Change, pp.1-12.

[10] Kenny, W. (1984). Energy Conservation in the Process Industries. 9th ed. Orlando: Academic Press.

[11] Li, H., Bao, W., Xiu, C., Zhang, Y. and Xu, H. (2010). Energy conservation and circular economy in China's process industries. Energy, 35(11), pp.4273-4281.

[12] Edgar, T. (1987). Current problems in process control. IEEE Control Syst. Mag., 7(2), pp.13-15.

[13] Jaber, J. (2002). Future energy consumption and greenhouse gas emissions in Jordanian industries. Applied Energy, 71(1), pp.15-30.

[14] Global Industrial Energy Efficiency Benchmarking. (2010). United nations Industrial development organization, pp.1-58.

[15] Energy Intensive Process Portfolio. (2011). Industrial Technologies Program, pp.1-11.

[16] Villar, A., Arribas, J. and Parrondo, J. (2011). Waste-toenergy technologies in continuous process industries. Clean Techn Environ Policy, 14(1), pp.29-39.

[17] Madlool, N., Saidur, R., Hossain, M. and Rahim, N. (2011). A critical review on energy use and savings in the cement industries. Renewable and Sustainable Energy Reviews, 15(4), pp.2042-2060.

[18] Boyd, G. and Pang, J. (2000). Estimating the linkage between energy efficiency and productivity. Energy Policy, 28(5), pp.289-296.

\section{Author Profile}

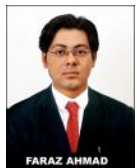

Faraz Ahmad is a Post Graduate student pursuing M.Tech degree in Thermal Engineering at (Institute of Technology and Management) I.T.M University, Gwalior, M.P, India.. He is a holder of a B.Tech Degree in Mechanical Engineering from Jawaharlal Nehru Technological University, Hyderabad which was awarded in 2013. His research interests include Sustainable Environmental Energy management systems.

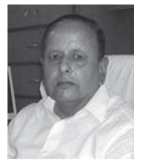

Dr. Ratan Kumar Jain got his B.E. (Hons.) from B.I.T.S. Pilani, M.E. (Thermal) Ph. D (Equiv.) and Ph.D. (Mechanical) from U.P. Technical University Lucknow. He has to his credit 64 research papers in international journals, international conferences etc. At present is working as Dean IAL at ITM University, Gwalior.

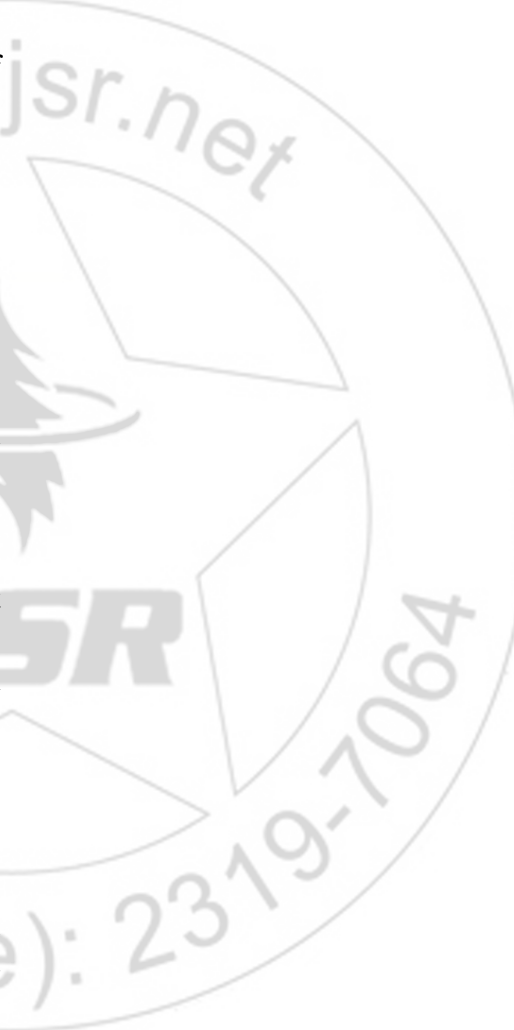

